\title{
Improving Packaging Logistics System: A Study Case of Camembert Cheese
}

\author{
Mushonnifun Faiz Sugihartanto ${ }^{1}$, Syarifa Hanoum ${ }^{1}$, Nalaputi Basoeki ${ }^{2}$, Elif Tiryakioglu ${ }^{2}$, Cynthia \\ Ferrier $^{3}$ \\ ${ }^{1}$ Department of Business Management, FCREABIZ, Institut Teknologi Sepuluh Nopember, Indonesia \\ mushonnifun@its.ac.id, syarifa@mb.its.ac.id
}

${ }^{2}$ Faculty of Engineering, Lund University, Sweden

nalaputi1996@gmail.com, eliftiryakioglu@gmail.com

${ }^{3}$ Arts et Métiers ParisTech - École Nationale Supérieure d'Arts et Métiers, France. cynthia.ferrier09@gmail.com

Received: 16/03/2021

Reviewed: 29/07/2021

Published: $31 / 07 / 2021$

Copyright $\odot 2020$ by the author (et al) and Jurnal Sosial Humaniora (JSH)

*This work is licensed under the Creative Commons Attribution International License (CC BY 4.0). http://creativecommons.org/licenses/by/4.0/ Open Access

\begin{abstract}
Subject Area: Logistics and Supply Chain Management Abstract

This research aims to assess the current packaging of Camembert cheese using the packaging evaluation method and propose suggestions to improve the efficiency of packaging logistics that would impact the efficiency of the entire supply chain. We engage all supply chain actors in evaluating the packaging features. The first packaging is not convenient as its weight and cost are pretty high for cheese. The secondary packaging is deemed less efficient, whilst the tertiary packaging is not optimal in traceability. Speaking of cost, environmental impacts, especially impact on other features in the supply chain, we propose solutions to replace the circular wooden box of the cheese with a cardboard box with a round shape. Then, only the cardboard trays will be used as secondary packaging all along the supply chain. These combined solutions reduce the handling work, the packaging material cost and provide more convenience for all actors.
\end{abstract}

Keywords: Supply Chain; Efficiency; Packaging Logistics; Packaging Evaluation Method.

\section{Introduction}

In recent decades, the development of the global economy has been increasing fast, broadening the supply chain's scope from locally to more globally. Consequently, products will rely on reliable packaging to keep products safe. Unfortunately, the packaging processes consume a vast number of resources, and it yields an impact on the environment as one of the major sources of waste is packaging (Kuo et al., 2019). In addition, the importance of packaging can bring a significant impact on the logistics performance of supply chains (Pålsson, 2018).

This research aims to evaluate and improve an existing packaging system of a particular product using the case study method. A case study of camembert cheese is chosen to analyse the product packaging system and supply chain systematically. By improving the packaging logistics performance, cost-efficiency can be achieved, and environmental waste can be reduced. 


\section{Methodology}

This study case was conducted by using packaging performance methodology by Pålsson (2018) adopted and developed from the 'packaging scorecard' by Olsmats \& Dominic (2003) that covers the current supply chain mapping by evaluating and improving packaging system. Figure 1 illustrates a systematic approach to map the overall supply chain performance with individual packaging features. Each packaging level will be evaluated to gain the big picture of the current performance and to identify some potential improvement areas. Some solutions will be suggested, including the trade-offs between solutions.

Figure 1. Packaging Evaluation Method

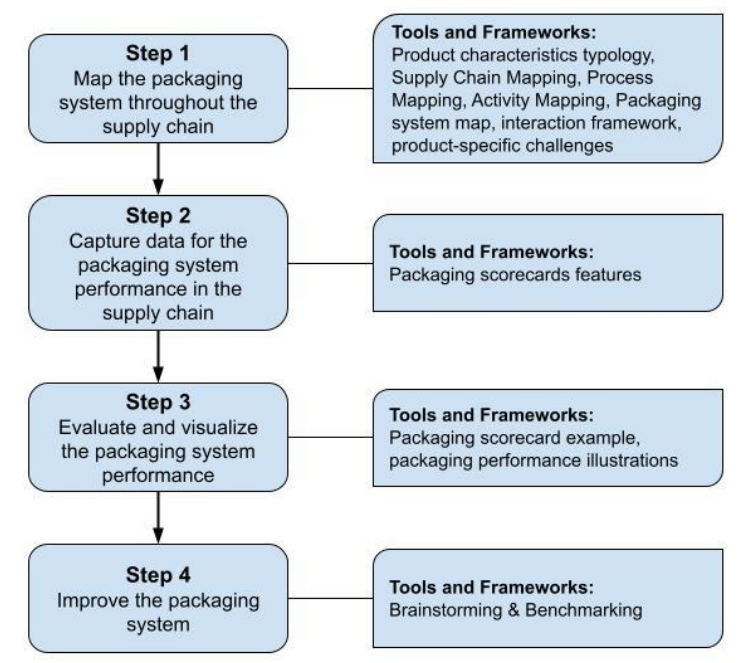

Data collection was conducted continuously during step 1 and 2. Gaining primary data was significantly important through observation and interviews to provide solutions quickly and improve the current system (Klose et al., 2002). Therefore, we collected primary empirical data through interviews with many actors along the supply chain. We confronted the fieldwork findings with the theoretical foundation to see the possible solutions or even strengthen the argumentation of the proposed solution.

\section{Result and Discussion}

\section{Step 1: Map the Packaging System Throughout the Supply Chain}

In this step, the product characteristics were identified, and their impacts on the packaging and map the packaging system are mapped throughout the supply chain network. Once the characteristics and impact on the packaging were identified, the analysis must be put into three layers of packaging: Primary, Secondary, and Tertiary documented in Tables 1,2 , and 3. 
Table 1. Specifications of Primary Package

Laminated Paper with OPP and Stapled Wooden (Self Documentation)

\begin{tabular}{|l|l|l|l|}
\hline \multicolumn{1}{|c|}{} & $\begin{array}{l}\text { 214x214mm (paper) } \\
115 \times 35 \mathrm{~mm} \text { (wooden box) }\end{array}$ \\
\hline Material & $\begin{array}{l}\text { Laminated paper with OPP } \\
\text { Stapled wooden }\end{array}$ & $\begin{array}{l}\text { Dimension } \\
\text { - The cheese is ageing in the box; thus, the veneer allows it to breathe and provides conditions for curing the } \\
\text { product by excluding any influence of off-odours on Camembert in its curing process. }\end{array}$ \\
\hline Provides physical protection for the product (Robertson, 2009).
\end{tabular}

Table 2. Specifications of Secondary Package

\begin{tabular}{|c|c|c|}
\hline Material & $\begin{array}{l}\text { Cardboard } \\
\text { Plastic }\end{array}$ & $\begin{array}{l}385 \times 240 \times 98 \text { mm (cardboard tray) } \\
400 \times 300 \times 108 \text { mm (plastic tray) }\end{array}$ \\
\hline Reason & \multicolumn{2}{|c|}{$\begin{array}{l}\text { - The product need aeration for the refining process through distribution } \\
\text { - The cardboard trays allow the product to breathe and restrict the accumulation of gases and moisture. } \\
\text { - Withstand the low temperature and protect the product during the transportation process. } \\
\text { - Increases the stackability of load. }\end{array}$} \\
\hline
\end{tabular}

Table 3. Specifications of Tertiary Package
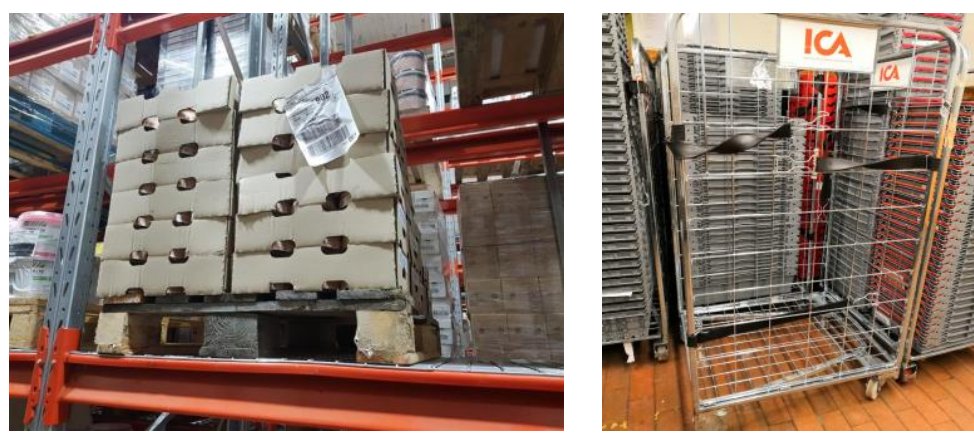


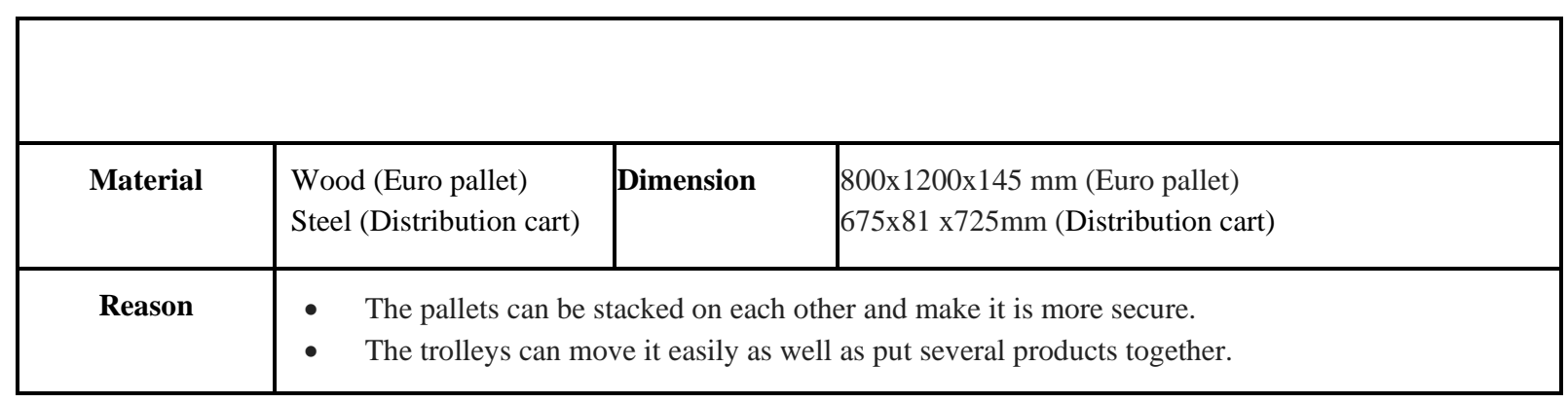

Once we have identified each layers' characteristics, we mapped them into a supply chain map, in Figure 2, to understand how the package is currently used during the distribution process. As illustrated in Figure 2, the logistic process starts at the production plant in Normande (France). First, the primary packaging includes wrapping the matured cheese with paraffin paper to keep the quality and put the cheese in a wooden box. The secondary package follows the first packaging by putting the product in the carton box, sealing off the box is then sealed and stacking them each other in the pallet as the tertiary package. The entire pallet contains 100 boxes, and it is wrapped by using plastic to keep it stable. All the packages are shipped to suppliers by using a cold chain truck provided by third-party logistics. The temperature should be kept between 0-4 degrees Celsius.

Figure 2. Supply Chain Map in Coeur de Lion Production Plant in Normande

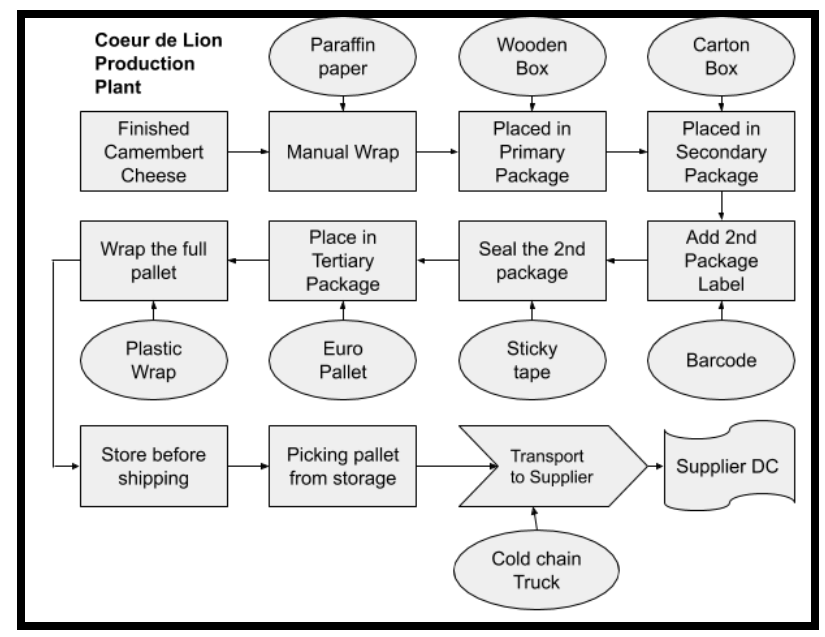

Figure 3 illustrates the logistic activities when the packages arrive at three different stages in the Camembert Cheese supply chain: at Lactalis Supplier Denmark, at ICA (One of the Supermarket brand in Sweden), Central Distribution Center (DC) in Gothenburg, and ICA Regional Warehouse in Stockholm, Borlange, and Helsingborg. At the Denmark supplier, the cheese was unloaded from the truck to the supplier's warehouse. After checking and scanning the barcode (to update data), the cheese is then stored in the supplier until the order from their buyer coming. Once the order comes, the cheese is shipped in full pallet to ICA Central DC in Gothenburg.

In the ICA Central DC in Gothenburg, the cheese is stored around 1-2 days before being delivered to regional DC. When the time to deliver comes, the pallet is unwrapped, and each box is placed in the new 
pallet as the order from regional DC comes at a smaller amount and never reaches the full pallet. After scanning the barcode, the cheese is re-wrapped and loaded to the truck and sent to ICA Regional Warehouse in Stockholm, Borlange, and Helsingborg. Once the products arrived in Stockholm, Borlange, or Helsingborg, the products are unloaded stored for around 2 to 3 hours before they are delivered directly to retailers. The plastic was unwrapped, and the box was placed into the plastic crate. Then, Camembert cheese is cross docked with other products in the ICA's trolley.

The products are scanned, unpacked, and placed in the customer racks at the stores at the retailer. The retailers are responsible for the packages (carton, plastic, and others.) being correctly handled. Then, the empty plastic crate boxes are shipped back to ICA Regional DC.

Figure 3. Logistic Activities at the three different stages of the Camembert Cheese supply chain

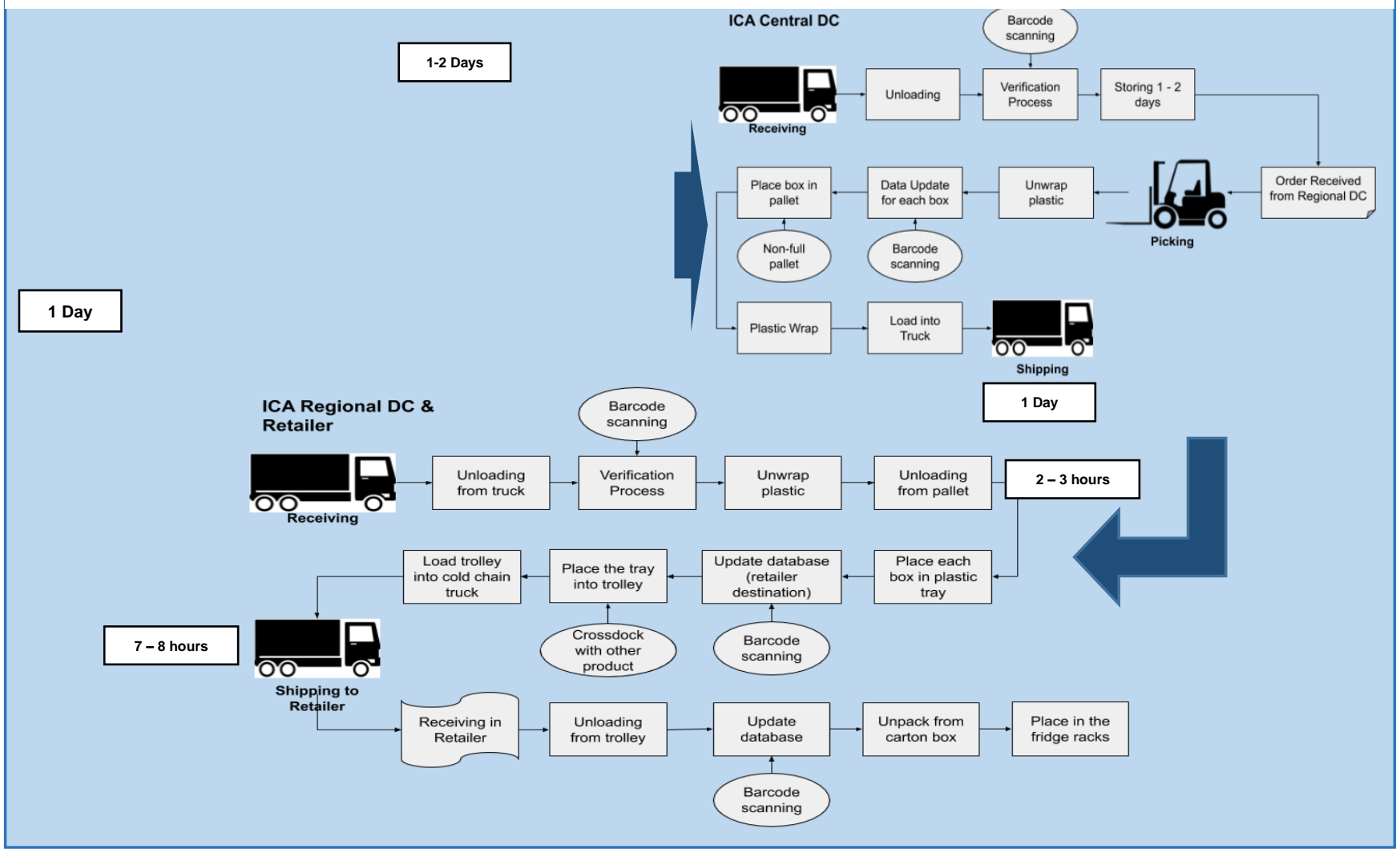

Having identified all the package handling along the supply chain, we identify the challenges that occurred at each stage and document them in the packaging system map in Figure 7. The Camembert cheese is packed in a cylindrical shape wooden box, traditionally. The product that is distributed through the supply chain conceives underutilised space in the trucks due to the shape of the primary package, which might lead to damages on product and destabilisation of loads. The other challenge is that the product itself is the product of a region, so it is supposed to be produced in the Normandy region of France and transported with cold chain trucks from France to the retail stores. Those challenges have influences on supply chain efficiency through monetary and sustainability. 
Figure 4. Packaging system map in the Camembert supply chain

\begin{tabular}{|c|c|c|c|c|}
\hline Producer & Supplier warehouse & Central DC & Regional DC & Retailer \\
\hline $\begin{array}{l}\text { Primary packaging: } \\
\text { sheet of paper } \\
\text { combined with OPP + } \\
\text { sliced wood veneer box }\end{array}$ & $\begin{array}{l}\text { Primary packaging: } \\
\text { sheet of paper } \\
\text { combined with OPP + } \\
\text { sliced wood veneer box }\end{array}$ & $\begin{array}{l}\text { Primary packaging: } \\
\text { sheet of paper } \\
\text { combined with OPP }+ \\
\text { sliced wood veneer box }\end{array}$ & $\begin{array}{l}\text { Primary packaging: } \\
\text { sheet of paper } \\
\text { combined with OPP + } \\
\text { sliced wood veneer box }\end{array}$ & $\begin{array}{l}\text { Primary packaging: } \\
\text { sheet of paper } \\
\text { combined with OPP + } \\
\text { sliced wood veneer box }\end{array}$ \\
\hline $\begin{array}{l}\text { Secondary packaging: } \\
\text { cardboard box }\end{array}$ & $\begin{array}{l}\text { Secondary packaging: } \\
\text { cardboard box }\end{array}$ & $\begin{array}{l}\text { Secondary packaging: } \\
\text { cardboard box }\end{array}$ & $\begin{array}{l}\text { Secondary packaging: } \\
\text { cardboard box + plastic } \\
\text { tray }\end{array}$ & $\begin{array}{l}\text { Secondary packaging: } \\
\text { cardboard box + plastic } \\
\text { tray }\end{array}$ \\
\hline $\begin{array}{l}\text { Tertiary packaging: } \\
\text { pallets wrapped with } \\
\text { plastic film }\end{array}$ & $\begin{array}{l}\text { Tertiary packaging: } \\
\text { pallets wrapped with } \\
\text { plastic film }\end{array}$ & $\begin{array}{l}\text { Tertiary packaging: } \\
\text { pallets wrapped with } \\
\text { plastic film }\end{array}$ & $\begin{array}{l}\text { Tertiary packaging: } \\
\text { trolley }\end{array}$ & $\begin{array}{l}\text { Tertiary packaging: } \\
\text { trolley }\end{array}$ \\
\hline
\end{tabular}

\section{Step 2 \& 3: Evaluation and Visualisation of Packaging System with the Scorecard Method}

\section{Primary Packaging}

Figure 5 illustrates the correlation between the importance and satisfaction level of primary packaging performance ranging from below average to very high between actors. The high level of satisfaction criteria is apportionment, promotional attributes, hazard substances, and track \& trace capability. The primary packaging has an authentic design that differs from other competitors, which could positively affect promotional attributes and make it easy to track and trace the products.

The criteria with the low satisfaction level are security, convenience, weight/volume efficiency. The low tightness of packaging makes it less secure as it is easy to take the product out of the packaging. The packaging material and double-pack process are not easy to handle.

Figure 5. Primary Packaging Score and Scatter Diagram of the Evaluation
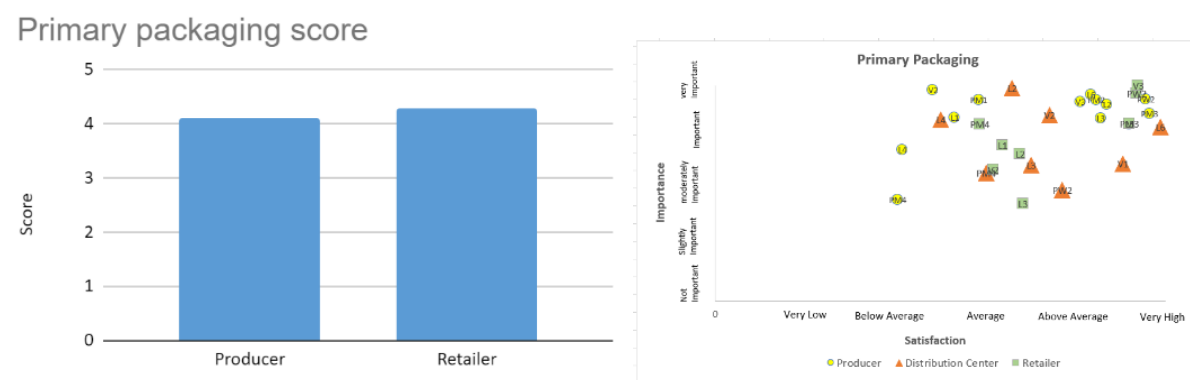

\section{Secondary Packaging}

The scorecard evaluation results of the secondary packaging system are represented in figure 6 . The producer's secondary packaging evaluation score is 3.4; the areas that require improvements are volume efficiency and the packaging cost of the secondary packaging. The score in the warehouse is 4.0, reasonably high as there are not many packaging features required at that stage. Some improvements are needed in volume and weight efficiency, and stackability of the packaging.

The retailer's secondary packaging evaluation scores from Distribution Center's side is 3.6 and from the Retailer's side is 3.59. The main features that must be considered for further improvement are unitisation, volume efficiency, stackability. The performance depreciation of these features might be caused 
by the interaction with the primary package, which has authentic shape and size to restrain filling efficiency of the loads and leads air transportation.

Figure 6. Secondary Packaging Score \& Scatter Diagram of the Evaluation
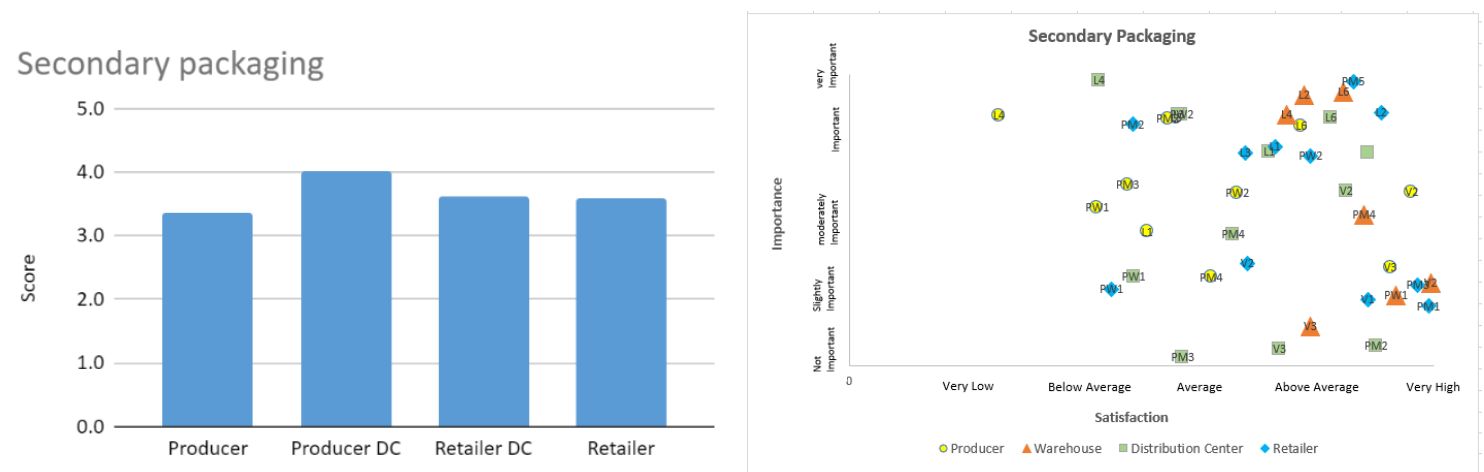

\section{$\underline{\text { Tertiary Packaging }}$}

According to figure 7, the overall score of tertiary packaging is very high for almost all attributes. There is an attribute that has a low score due to some reasons. It is a score of protection and containment in DC. It was assessed low because the cheese is already protected by the primary and secondary package, which is enough to protect its product.

Figure 7. Tertiary Packaging Score \& Scatter Diagram
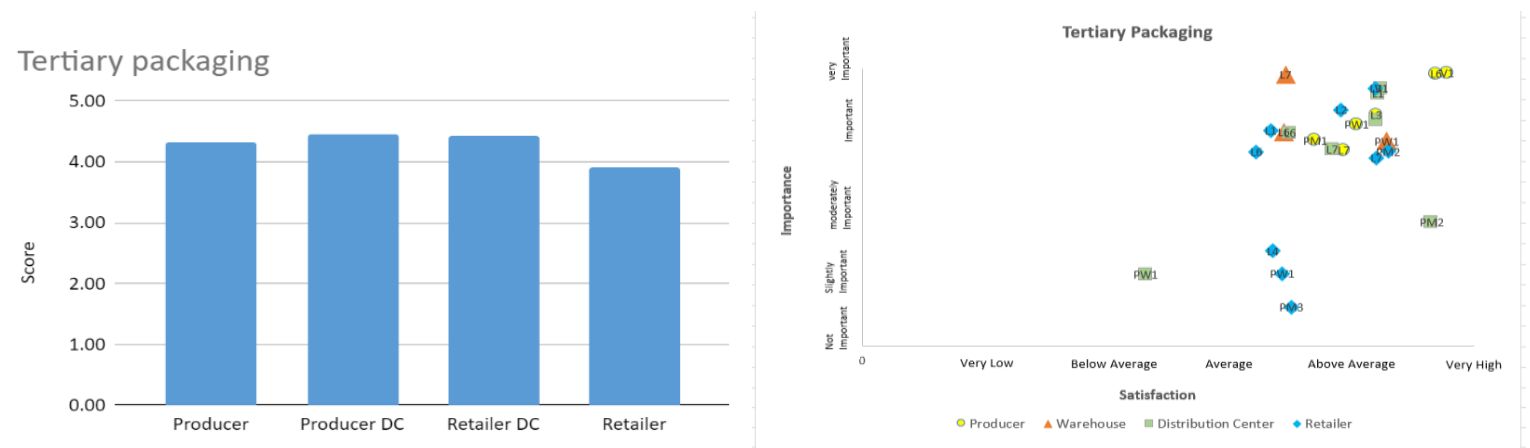

Figure 8 represents the normalised importance and satisfaction total score of the different packaging levels of Camembert cheese in all the supply chain. It is observed that the secondary package has a minor score for all the supply chain, which means that the leading optimisation should be focused on this level.

Figure 8. Comparison in normalised score between all actors in all supply chain

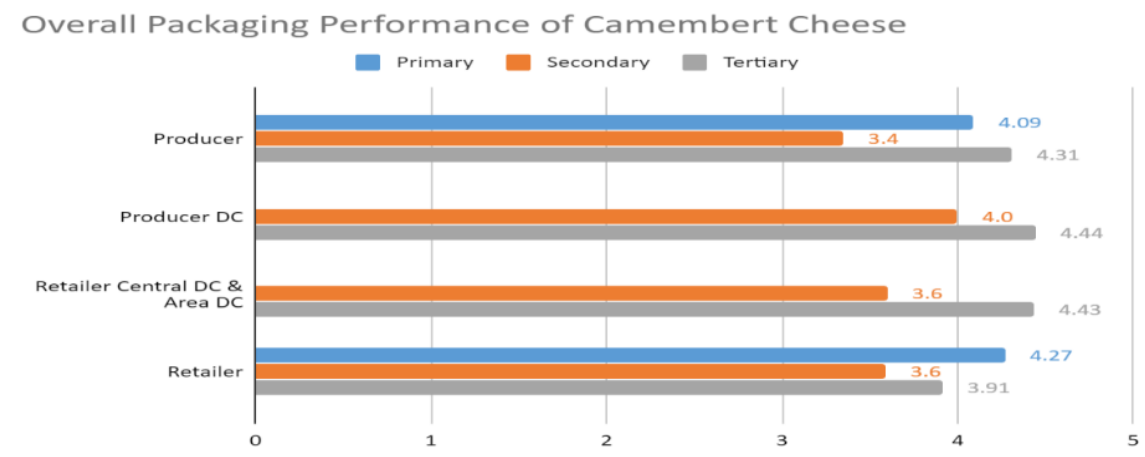




\section{Step 4: Improve the Packaging System}

The performance of each packaging level evaluates the packaging system performance. The scatter diagrams mark the features, and each packaging level's performance is evaluated for further improvements. For each level of the packaging system, possible improvements are identified as follows: Convenience and Weight and Cost efficiency in the primary packaging, convenience in the secondary packaging, and traceability in the tertiary packaging. Based on these areas of improvements, we recommend three different modifications to improve the packaging system in different levels, considering packaging logistics demand and other requirements.

\section{Suggestion 1: Modification of the Primary Package}

The current primary package concept has opportunities for improvements for two reasons. First, the current package consists of two elements: a wrap sheet and a wooden box, a rounded shape box. There are two possible options for the new packaging system:

\section{Paper wrapped Packaging}

The first idea is removing the outer box of the primary packaging and using OPP (Oriented Polypropylene, a flexible packaging plastic) laminated paper as the only primary packaging. This modification is inspired by different kinds of soft cheese (e.g., brie) sold in a wrapped laminated sheet in the market. The wrapped sheet may also be replaced by sheets made of other polymers, aluminium, or wax, but that would not change the last considered problem (Coulon, D.). The paper would be slightly different from the one used in the current packaging, as it is wrapped loosely in the current packaging and not sealed properly. The paper will be sealed using the attached label for this solution, making it wrapped tightly but easy to open.

\section{Wrapped in Rectangular Paper Box}

The second idea is replacing the rounded-wooden box with the paper box in a square shape. This modification replaces the wooden material of the secondary packaging part with a rectangular shape paper box. This modification will provide the necessary physical protection that the product requires and gives better stackability throughout the distribution process.

\section{a. Logistics Performance Evaluation}

The Paper wrapped packaging has less packaging weight per unit, and in the whole supply chain, it may create volume efficiency. The current packaging has some space remaining inside the box that decreases the coefficient of fullness, whereas this space will be removed along with the removal of the box. The rectangular paper box modification leads to improvement of stackability. The shape of the paper packaging is square, which provides better stackability due to the corner strength of the paper box. The product also has proper protection due to the maintenance of the outer box.

\section{b. Cost Efficiency}

The paper wrapped packaging is more economical since it only includes one layer of packaging material as compared to the current packaging and the second modification. It also decreases the 
packaging weight per unit, and the whole supply chain may result in weight efficiency. The rectangular paper box offers lower packaging costs than the current packaging. The cost of paper box packaging is $\$ 0.2 /$ unit, whereas the cost of the wooden box is $\$ 0.5 /$ unit.

\section{c. Environment Impact}

For the environmental impact of both solutions, material recyclability is one of the quintessential aspects to consider. The two suggested modifications and the current packaging concise the same packaging material, OPP laminated paper consisting of paper and plastic laminate layers. This multilayer material is hard to separate and cannot be recycled. However, it provides high protection for the cheese and increases the shelf-life of the product. This contributes to food waste prevention. The current packaging uses a wooden box that is not recyclable and ends up at incineration for energy recovery.

\section{Suggestion 2: Modification of the Secondary Package}

We recommend simplifying the secondary packages by keeping one secondary package to save cost and increase the handling time efficiency while trying to get the same packaging system performance. The DC should compromise their secondary packaging choice, either using the cardboard box from the producer or the same plastic trays as the DC would use from the beginning. The cardboard boxes can be redesigned to replaces the plastic trays and ICA's requirements from the secondary package so ICA would switch from cardboard. Suggestions are named Returnable Plastic Tray on Whole Supply Chain or Cardboard Boxes on Whole Supply Chain.

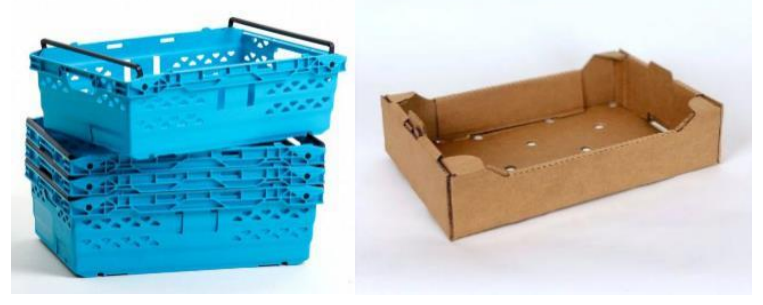

\section{a. Logistics Performance Evaluation}

Eliminating one of the secondary package options would save time at the DC. The task would be simplified by only moving the secondary packaging from the producer warehouse to a trolley. At the retailers, they need to take care of only one package after they unpack; either they recycle the cardboard boxes or send back the plastic trays with the other ones. Thus, it is less time-consuming for the retailer. 


\section{b. Cost Efficiency}

The two solutions considered have very different impacts on cost-efficiency. First, the cost-saving evaluation is the producer side by using the plastic trays as ICA. These trays are rented to a company, as Svenska Retursystem; hence it would require investments. Having similar trays might not be easy considering that the producer is located in France, not in Sweden. That would also mean the cost of transporting the empty trays from Sweden to the producer. On the other hand, should the cardboard box be redesigned, the investment takes place from the producer side and its supplier because they may have to change some steps of the boxes' production or change supplier. Although that should be considered, there might not be a considerable cost saving of the producer, the modification would improve the handling time efficiency, and labor cost. Thus, the producer has to pay so that ICA could profit from it. The modification of this application has required collaboration between the retailer and the producer on investment.

\section{c. Environment Impact}

The reusable trays would be a better option for decreasing packaging materials that go waste, so it seems to be a better solution from an environmental point of view. However, the transportation of empty trays as ICA's one through different countries until the producer place would have a higher environmental impact. The cardboard boxes are for single use after they transport the product, they are recycled. As they are recycled, the environmental impact of the secondary package will be reduced (Sustainable SA, n.d.).

\section{Suggestion 3: Improve the Traceability}

Currently, a barcode is used to track the position of Camembert cheese. This works quite well. However, it can be scaled up to be more trackable and traceable. Therefore, our suggestion to improve packaging performance is by implementing RFID technology. In recent decades, this technology has been developed and started to be used in various applications such as inventory tracking and building access (Zhu et al., 2012).

The implementation of RFID might need some investment of the manufacturer, supplier, distributor, and retailer. However, this can also be implemented to other products. According to Zhu et al. (2012), there are two types of RFID tags: active and passive. The main difference is that the former has a battery that can transmit a broadcast signal back to the RFID reader, while the latter does not have it. Since the passive tag is cheaper than the active tag, we recommend using a passive tag in camembert cheese.

\section{a. Logistics Performance Evaluation}

The implementation of RFID will bring some enormous effects on overall logistics performances. First, It can improve the traceability of goods that are currently being conducted manually by the worker by scanning the product individually. Hence, the internal flows can be optimised and the overall cost can be reduced (Regattieri et al., 2014). 


\section{b. Cost Efficiency}

Initially, implementing RFID will increase the initial cost of developing the system and setup and labelling goods to enable traceability (Henrik \& Vahid, 2014). In 2000, the cost of RFID tags was about a dollar. Even by using extensively will not be possible to reduce the cost drastically. However, instead of looking to the "added cost", a firm should evaluate how much the "added value" will be generated (Zhu et al., 2012). Since camembert cheese is considered a low-value product, it might be costly to implement it to apply this technology to camembert cheese.

\section{c. Environment Impact Evaluation}

The real-time information that RFID yields will generate better planning of raw materials to the manufacturers. Since the data is delivered in real-time, it will reduce some product probabilities to be defective, damaged, and others (Dukovska-Popovska et al., 2010). Hence, this will reduce unnecessary truck deliveries.

\section{Conclusion}

Camembert cheese is a perishable product that requires good protection and careful handling process throughout its supply chain. Each packaging level was evaluated with all the relevant features using the scorecard method. It was observed that sometimes scores in one feature could depend on the interaction between each level of packaging; for example, the volume efficiency of the secondary packaging was highly affected by the round shape of the primary packaging.

Some packaging features can be improved to achieve more efficient packaging logistics. It is important to remember that if a feature is changed, it may influence all of the other scores in the features of that specific level and other packaging levels. Based on the packaging system performance evaluation results, three different suggestions were proposed for improving the current packaging system. They are targeted to enhance the performance of a packaging unit in the selected areas while fulfilling and without compromising the logistical demands and product requirements.

The first suggestion is to replace the current primary wooden packaging with a paper box. The new modification provides better logistic performance, lower environmental impact, higher cost-saving and recyclability. The second suggestion is applying the sole, as opposed to double, secondary package. Redesign cardboard trays aim to fulfil the requirements of the supply chain actors while decreasing the cost of secondary packaging units and improving the efficiency of handling processes. The third suggestion is to apply the RFID tag to improve the traceability of the loads. The application of RFID systems on the tertiary packaging will reduce environmental impact logistics by optimising the product deliveries transnational level. Unfortunately, the cost of such an implementation is very high, and it is too hard to involve all the retailers.

Out of all the proposed suggestions, replacing the primary packaging with a cardboard box in a rectangular shape and redesigning the cardboard of secondary packaging would be the final suggestion of this project. The use of a card box for primary packaging will lower the cost and increase user-friendliness. 
It also has a better environmental aspect as the card box is recyclable. However, it needs to be carefully designed to mimic the visual perception of the wooden box. Thus, it will not affect consumer perception negatively, and the sales will not decrease due to the change of packaging. The cardboard redesigning process will need to consider the whole supply chain, especially in-retailer. As the purpose of this modification is to avoid double secondary packaging, the redesign process should involve the dimension and shapes required to fit the tertiary packaging in all the supply chain. This would take some time to implement as collaborations must be done between the actors throughout the chain. By implementing these suggestions, the packaging system would be more efficient and positively affect all parties in the Camembert Cheese supply chain. This research also can be a foundation for other cheese manufacturers to develop their packaging logistics system.

\section{References}

Dukovska-Popovska, I., Lim, M. K., Steger-Jensen, K., \& Hvolby, H.-. (2010). RFID technology to support environmentally sustainable supply chain management. 2010 IEEE International Conference on RFID-Technology and Applications, 291-295. https://doi.org/10.1109/RFID-TA.2010.5529916

Henrik, A. R., \& Vahid, M. (2014). Effects on logistic operations from RFID- and EPCIS-enabled traceability. British Food Journal, 116(1), 104-124. https://doi.org/10.1108/BFJ-03-2012-0055

Klose, A., Speranza, M. G., \& Van Wassenhove, L. (2002). Quantitative Approaches to Distribution Logistics and Supply Chain Management. https://doi.org/10.1007/978-3-642-56183-2

Kuo, T. C., Chiu, M. C., Chung, W. H., \& Yang, T. I. (2019). The circular economy of LCD panel shipping in a packaging logistics system. Resources, Conservation and Recycling, 149(November 2018), 435444. https://doi.org/10.1016/j.resconrec.2019.06.022

Olsmats, C., \& Dominic, C. (2003). Packaging scorecard - A packaging performance evaluation method. Packaging Technology and Science, 16(1), 9-14. https://doi.org/10.1002/pts.604

Pålsson, H. (2018). Packaging Logistics: Understanding and Managing the Economic and Environmental Impacts of Packaging in Supply Chains. Kogan Page Publishers.

Regattieri, A., Santarelli, G., Gamberi, M., \& Gamberini, R. (2014). The Use of Radio Frequency Identification Technology in Packaging Systems: Experimental Research on Traceability. Packaging Technology and Science, 27(8), 591-608. https://doi.org/https://doi.org/10.1002/pts.2052

Sustainable SA. (n.d.). 3Rs - Reduce, Reuse \& Recycle. Retrieved December 17, 2019, from http://www.sustainablesanantonio.com/practices-technology/reduce-reuse-recycle/

Zhu, X., Mukhopadhyay, S. K., \& Kurata, H. (2012). A review of RFID technology and its managerial applications in different industries. Journal of Engineering and Technology Management - JET-M, 29(1), 152-167. https://doi.org/10.1016/j.jengtecman.2011.09.011 